\title{
Atenção Compartilhada e Identificação Precoce do Autismo
}

Cleonice Bosa ${ }^{12}$

Universidade Federal do Rio Grande do Sul

\section{Resumo}

O objetivo desse artigo é discutir sobre o desenvolvimento da habilidade de atenção compartilhada e suas implicações para a identificação precoce do autismo. A revisão da literatura baseia-se nas teorias do desenvolvimento e em evidências empíricas. Para tanto, parte-se de uma discussão mais ampla acerca do desenvolvimento da comunicação e do conceito de intencionalidade, na qual inserem-se as principais questões sobre a habilidade de atenção compartilhada (AC). Subseqüentemente, focaliza-se a importância da presença da habilidade de AC no repertório comportamental da criança. Argumenta-se que déficits na habilidade de AC estão entre os mais fortes preditores de comprometimento do desenvolvimento infantil, em especial do autismo. Palavras-chave: Desenvolvimento sócio-comunicativo; atenção compartilhada; autismo; identificação precoce.

\section{Joint Attention and Early Identification of Autism}

Abstract

The aim of this article is to discuss the development of the joint attention ability and its implications for the early identification of autism. The literature review is based on both developmental theories and empirical evidence. For this purpose, a wider discussion about the development of communication and the concept of intentionality is included within which the issues about the joint attention ability are inserted. Subsequently, the importance of the presence of the JA ability in the child's behavioral repertoire is focused. It is argued that the JA deficits are among the strongest predictors of developmental disorders, in particular of autism.

Keywords: Socio-communicative development; joint attention; autism; early identification.

Apesar do tema "atenção compartilhada" (AC) dominar a literatura nas áreas da psicologia do desenvolvimento e da psicopatologia, observa-se que as discussões têm sido, em alguma medida, fragmentadas. Isso porque a ênfase ora é colocada na descrição dos comportamentos que compõem essa habilidade e dos períodos de sua emergência, ora no seu papel enquanto preditor de comprometimentos futuros no processo de desenvolvimento social. Raramente a habilidade de atenção compartilhada tem sido discutida a partir dos seus fundamentos epistemológicos, qual seja, das noções de intencionalidade e seu papel na comunicação. As razões pelas quais essa habilidade tem constituído um dos mais fidedignos preditores de problemas no desenvolvimento social, comparada a outros comportamentos sociais (ex: sorriso e contato ocular), também não têm sido claramente abordadas. Outro aspecto a ser criticado é a compreensão da $\mathrm{AC}$ enquanto competência interna da criança, relativamente independente do contexto familiar - questão crucial no caso de autismo.

'Endereço para correspondência: Instituto de Psicologia, Departamento de Psicologia do Desenvolvimento e da Personalidade, Ramiro Barcelos, 2600, Porto Alegre-RS, 900035-003. Fone: (51) 3309507; Fax: (51) 3304797. E-mail: cleobosa@conex.com.br

${ }^{2}$ Esse trabalho é parte integrante da tese de doutorado da autora, subsidiada pelo CNPq. Versão preliminar desse manuscrito foi apresentada na XXX Reunião Anual de Psicologia, Brasília, 2000.
O presente trabalho busca sanar, em parte, essas questões, introduzindo na literatura nacional uma discussão sobre as dificuldades acerca do conceito de comunicação e sua relação com o de intencionalidade para, em seguida, abordar a questão da definição de atenção compartilhada. As formas de expressão comportamental e períodos de emergência da AC no desenvolvimento típico também serão apresentadas. Seguem-se discussões a respeito dos déficits de AC no autismo, sua relação com o contexto familiar, bem como dos principais modelos teóricos explicativos desses comprometimentos.

\section{Desenvolvimento da Comunicação Intencional}

A primeira tarefa que se apresenta para quem se propõe a discutir acerca do desenvolvimento da comunicação é, evidentemente, tratar da questão da definição do termo. Considerando-se que uma definição única e consensual é improvável, discute-se a respeito das dimensões que caracterizariam os processos comunicativos.

Comunicação tem sido definida, por exemplo, como uma complexa interação entre dois ou mais indivíduos, envolvendo processos cognitivos, tais como alternância de papéis, percepção, codificação e decodificação de sinais (Hargie, Saunders \& Dickson, 1987). Tal definição traz, implícita, a noção de transferência de informação, seja por meios verbais ou não-verbais, e ainda, atrela-se a 
outra questão ainda mais fundamental - se essa transmissão ocorre intencionalmente. Um aspecto ressaltado por Bates (1976) é que nem todo comportamento (verbal e não-verbal) é comunicativo, defendendo a tese de que é o conceito de intenção que o caracteriza como tal. Essa autora trabalha com a ampla noção de que intencionalidade está associada à persistência em alcançar um objetivo, embora não possamos esquecer que a complexidade da questão da definição de intenção remonta à idade média. Não há, conforme Messer (1994), concordância a respeito da inclusão do conceito de intencionalidade como pré-requisito para a comunicação. Isso ocorre principalmente em relação à questão da percepção da intencionalidade pelo receptor da informação, que pode tomar uma das duas formas, com diferentes ramificações, detalhadas a seguir.

A primeira forma envolve a transmissão da informação que pode ser comunicada intencionalmente: e, a) percebida como intencional e acurada (ex: bebê chora e olha para mamadeira - mãe dá a mamadeira para o bebê - bebê acalma-se); b) percebida como intencional, mas não acuradamente (ex: duas pessoas cochichando sobre uma situação qualquer e uma terceira percebendo o fato como se ela fosse o objeto do cochicho); c) percebida, mas não acuradamente nem como intencional (ex: interpretar um ato deliberado como um acidente); e, d) absolutamente não percebida (ex: bebê aponta para um objeto e olha para o adulto - adulto ignora o bebê).

A segunda forma seria a de que pode haver uma comunicação não-intencional, porém percebida ou não como intencional. Por exemplo, movimentos do corpo ou o jeito de olhar podem fornecer informações sobre o pensamento e estado afetivo de uma pessoa sem que haja intenção de comunicar tais pensamentos ou emoções (pelo menos conscientemente!). Outro exemplo, seria o choro de recém-nascidos, o qual, apesar de não envolver intenção de comunicar (para alguns teóricos, mas não para todos; ver discussão abaixo), fornece aos seus cuidadores informações fundamentais a respeito das necessidades do bebê.

Enquanto para alguns teóricos (ex: Kaye, 1982; Vygotsky, 1978), as ações iniciais do bebê não envolvem qualquer intenção para comunicar-se, mas são interpretadas pelos adultos como sendo intencionais, para outros (ex: Trevarthen, 1979), a intencionalidade seria uma capacidade inata que já existiria de forma latente no repertório comportamental do bebê. Então, conclui-se que na raiz de qualquer definição de comunicação intencional encontramse pressupostos epistemológicos diferentes, enfatizando as capacidades inatas ou ambientais como determinantes do desenvolvimento social e da comunicação.

Importantes contribuições nessa questão provêm das conclusões de Fogel (1993) e Bruner (1990/1997). O primeiro critica o reducionismo existente ao tratar-se a interação social como um conjunto de respostas discretas a eventos prévios igualmente discretos. Nessa mesma linha de raciocínio, Lyra e Seidl de Moura (2000) chamam a atenção para a natureza auto-organizadora dos sistemas de desenvolvimento, privilegiando os momentos de estabilidade e mudança que emergem e desenvolvem-se na comunicação inicial mãe-bebê e a importância de compreender-se esse processo inserido num contexto sóciocultural. Dessa forma, depreende-se que a interação social é apenas parcialmente "planejada", caracterizandose mais como um sistema aberto sujeito a contínuas mudanças e adaptações durante o processo interativo. Do mesmo modo, os estudos realizados por Lyra (2000) e Pantoja (2000) ressaltam que ambos os parceiros da díade mãe-bebê estão implicados no processo de interação, o qual caracteriza-se por ser um sistema dinâmico: os bebês fornecendo pistas sobre seus estados e as mães apropriandose destas informações e tomando-as como guias para o seu próprio comportamento.

Bruner (1990/1997), por outro lado, faz uma tentativa de integração das duas formas (biológicas e culturais) de conceber o desenvolvimento dos processos comunicativos, embora privilegie o papel da cultura, em particular:

"o substrato biológico, os assim chamados universais da natureza humana, não causam a ação; sobre ela exercem, no máximo, uma restrição, ou para ela constituem uma condição (....) a cultura e a busca por significado dentro da cultura são as causas adequadas da ação humana” (p. 28).

Uma das linhas de argumentação em favor do interacionismo na abordagem do comportamento social vem da etologia. Nesse enfoque, a discussão de uma dicotomia entre inato e adquirido perde o sentido, sendo enfatizada a importância da focalização dos processos através dos quais os fatores genéticos e ambientais interagem e exercem seus efeitos (Carvalho, 1998).

Esgotada a discussão acerca dos determinantes do comportamento sócio-comunicativo, deflagra-se o problema de como identificar a intencionalidade da comunicação. Sendo "intenção" um constructo (não observável), é aparentemente fácil inferi-la - o difícil é contextualizá-la: como e quando ocorre. Conforme Messer (1994), igualmente árduo, é atribuir-lhe um ponto de emergência no desenvolvimento, identificando sinais de sua expressão, cujas mudanças são internas e dependentes da evolução nos modos de pensar da criança. Acrescentaríamos a isso, a dependência das particularidades da interação de cada díade e do contexto sociocultural em que ela está inserida, a exemplo do que Seidl de Moura e Ribas (2000) fizeram. 
Na tentativa de discutir o problema da identificação de intencionalidade recorreu-se ao modelo de Bates, Camaioni e Volterra (1979) as quais propuseram uma perspectiva comportamental para o estudo do comportamento intencional. Segundo essas autoras, para que um comportamento seja considerado comunicativo, é necessário que resulte em mudanças previsiveis no comportamento dos outros. Dessa forma, durante a interação adulto-criança, o comportamento intencional poderia ser inferido com base em quatro respostas observáveis: 1) a existência de um contexto indicando que uma meta é desejada pela criança; 2) algum movimento ou som produzido pela criança, incluindo alternância do olhar entre o objeto e o adulto; 3) persistência do comportamento até que a meta inferida seja alcançada; 4) comportamento consumatório (confirmando a meta que a criança "tinha em mente"). As autoras basearam-se nas idéias do filósofo Austin (1962) em sua teorização sobre o desenvolvimento da comunicação intencional. Esse autor sugeriu que algumas sentenças não são apenas descrições de eventos mas eventos em si mesmas, isto é, atos que são executados cada vez que uma sentença é empregada (por exemplo, fazer perguntas, afirmações, promessas, etc.). Ele identificou três tipos de "atos de fala": locuções, ilocuções e perlocuções. Coube ao filósofo Searle (1965) focalizar, mais detalhadamente, a distinção entre atos locucionários e ilocucionários, propondo uma divisão de toda sentença em duas partes: o conteúdo proposicional (locução) e o performativo (força ilocucionária).

Partindo, então, da terminologia empregada por esses filósofos, Bates e colaboradores (1979) propuseram um estudo longitudinal sobre o desenvolvimento dos performativos durante o primeiro ano de vida da criança. As autoras concentraram seus estudos em dois performativos em especial: o imperativo e o declarativo. Dessa forma, gestos indicativos possuem uma função protodeclarativa, isto é, servem para fazer comentários a respeito do mundo circundante a outras pessoas, enquanto os comportamentos de pedido, ao contrário, servem a um propósito protoimperativo - gestos para obter assistência. As autoras sugeriram estágios para o desenvolvimento da comunicação intencional (perlocucionário, ilocucionário e locucionário), buscando investigar, em particular, os prérequisitos cognitivos para a passagem de um estágio a outro, com base na epistemologia genética piagetiana, mais especificamente, nos seis estágios do período sensóriomotor.

As autoras explicaram as locuções em termos de pronúncia de sons e construção de proposições. Conseqüentemente, uma locução requer o aparecimento da fala, sem contudo revestir-se de comunicação intencional. Psicologia: Reflexão e Crítica, 2002, 15(1), pp. 77-88
$\mathrm{O}$ ato ilocucionário, ao contrário, requer o uso intencional de sinais convencionais na execução de funções socialmente reconhecidas (ex: dar um comando, indicar a presença de objetos ou eventos), os quais podem vir acompanhados de gestos (ex: apontar). Por outro lado, no ato perlocucionário, ocorre a emissão de um sinal, o qual exerce um impacto no ouvinte, independente da intenção do emissor (ex: o choro de um bebê faminto e seu impacto na mãe - dar o leite).

As autoras argumentaram que a comunicação intencional distingue-se de outras respostas na medida em que envolve a coordenação entre gesto e olhar, em direção a um parceiro. As suas observações sobre a produção de gestos, tais como apontar, alcançar, mostrar e dar objetos, auxiliaram na teorização a respeito do desenvolvimento da comunicação intencional. O interessante do trabalho dessas autoras é a natureza dessa teorização, integrando os achados aos de outras áreas como a psicanálise e a etologia. Citam os trabalhos de Spitz (1968) e Bowlby (1969) ao abordarem o caráter inato de determinados comportamentos dos bebês (ex: sorriso) na manutenção da interação social. Porém, deixam clara sua posição epistemológica ao creditar o desenvolvimento da comunicação de imperativos e declarativos ao estabelecimento de uma relação meio-fim, correspondente ao estágio 5 do período sensório-motor piagetiano. Dessa forma, para as autoras, não haveria evidência de comunicação intencional anterior aos nove-dez meses de idade. Contudo, são cautelosas ao afirmarem que isso não significa que não haja comunicação antes dessa época, mas sim que o bebê não estaria ciente do propósito convencional dos seus sinais, uma vez que seria o adulto quem atribuiria intencionalidade às ações do bebê: "Apesar de não encontrarmos evidência de comunicação intencional nos primeiros quatro meses de vida, nós testemunhamos o desenvolvimento da intencionalidade em geral, em direção a metas tanto sociais quanto não sociais" (Bates e cols., 1979, p. 118).

Cada vez mais, tem se buscado enfatizar as abordagens pragmáticas do desenvolvimento da linguagem, isto é, o papel do comportamento verbal e não-verbal no ato comunicativo, levando-se em conta o contexto social em que a comunicação ocorre (Baron-Cohen, 1988). Os princípios comportamentais aplicados aos constructos não observáveis geraram muitos estudos empregando a metodologia de observação sistemática (Carpenter, Mastergeorge \& Coggins, 1983; Cirring \& Rowland, 1985). Isso possibilitou a investigação de questões pertinentes aos aspectos do desenvolvimento da interação social, comunicação intencional e aquisição de linguagem, e de como esses processos se inter-relacionam. Por exemplo, Lord e Magill (1989) afirmaram que a capacidade de 
compreensão verbal em bebês desenvolve-se a partir de múltiplas fontes de informação, incluindo a expressão facial dos cuidadores, direção do olhar, gestos, contexto afetivo e situacional, conferindo às palavras "significados" bem antes delas se tornarem "verdadeiros conceitos".

Bates (1976) salientou que um dos primeiros passos em direção à competência comunicativa é a "tarefa" do pais de atribuir significado ao comportamento do bebê. Isso é consistente com a posição de Vygotsky (1978) de que as ações iniciais do bebê não envolvem intenção de se comunicar. Tais ações podem ser uma resposta involuntária (chorar), outra menos randômica (levantar os braços) ou mesmo ter um propósito (alcançar um objeto). Entretanto, podem ser interpretadas pelos cuidadores como sendo intencionais. É interessante assinalar que essa noção é consistente com o conceito de "sensibilidade materna" (Ainsworth, Blehar, Waters \& Wail, 1978) e "enquadramento" (framing) parental (Kaye, 1982), os quais envolvem a noção de que a comunicação cuidador-bebê depende mais da habilidade do adulto em perceber os desejos necessidades deste do que das "intenções" do bebê posição que contrasta com as perspectivas inatistas de comunicação (Trevarthen, 1979). Esse último autor parte da premissa de que as habilidades sociais e cognitivas desenvolvem-se não somente a partir da interação com o meio mas como resultado da maturação de capacidades inatas. Em outras palavras, intencionalidade deriva da motivação básica de se relacionar com as pessoas desde o nascimento (intencionalidade latente) e desenvolve-se no contexto das fases diádicas e triádicas da comunicação.

\section{A Fase Diádica da Comunicação}

Para Trevarthen (1979), o período denominado de "subjetividade primária" corresponde àquele no qual o olhar e as expressões afetivas do bebê são seletivamente dirigidos e integrados ao comportamento social das pessoas (intersubjetividade). A comunicação envolve interação face-a-face e as trocas afetivas entre o bebê seus cuidadores precedem a atividade gestual. Evidências dessas idéias provêm de estudos acerca da preferência de recém-nascidos pela face humana a objetos inanimados (Bushnell, Sai \& Mullin, 1989; Walton, Bowe \& Bower, 1992). Esse período é seguido por uma fase na qual objetos podem ser compartilhados com pessoas (trocas triádicas), a qual será discutida no próximo item.

Independentemente das controvérsias em torno dessas posições, assinala-se que o movimento do bebê em direção a formas mais sofisticadas de comunicação resulta do reconhecimento do mesmo de que suas ações têm algum efeito nos outros, isto é, têm poder comunicativo. Nesse aspecto compartilhamos a idéia de diferentes autores ao postularem que o desenvolvimento da comunicação intencional, por parte do bebê, decorre de uma crescente compreensão do outro como um "agente intencional", isto é, pessoas que: a) possuem metas e agem ativamente para atingi-las (Carpenter, Nagell \& Tomasello, 1998); b) são capazes de compreender que nossas ações têm igualmente um propósito, seja este o de solucionar um problema (agentes de ação) ou de compartilhar experiências com relação ao meio (agentes de contemplação; Hobson, 1993); c) interessam-se e prestam atenção a coisas a seu redor. Inicialmente, o bebê é impelido a "seguir" o interesse que as pessoas expressam pelo meio circundante. Posteriormente, ele próprio passa a chamar a atenção dos outros para esses eventos ou para si próprio (Scaife \& Bruner, 1975), constituindo a fase triádica da comunicação.

\section{A Fase Triádica da Comunicação}

A fase triádica da comunicação emerge no segundo semestre de vida do bebê (Bates e cols., 1979; Carpenter e cols., 1998; Paul \& Shiffer, 1992; Scaife \& Bruner, 1975). Consiste, primordialmente, em comportamentos nãoverbais (gestos e vocalizações) para pedir ou rejeitar objetos/ações e comentários acerca do próprio self ou objetos/eventos. Enfatiza-se que tais comportamentos são acompanhados pelo desenvolvimento afetivo, o qual progride de simples expressões de sorrisos ou distress para diferentes emoções, tais como medo, ira e tristeza. Tal diferenciação na expressão afetiva auxilia a interação do bebê com o meio, pois permite a comunicação de estados internos.

No final do primeiro ano de vida, o bebê passa a utilizar palavras para expressar intenções. No período que vai dos 18 aos 24 meses, expande-se o leque de intenções expressadas, culminando com a capacidade discursiva. Tal habilidade manifesta-se na forma de, por exemplo, solicitar informações e mostrar-se "consciente" acerca das verbalizações do outro (Carpenter e cols, 1998).

Diferentes estudos demonstraram que existe uma seqüência no desenvolvimento da comunicação (Carpenter e cols., 1983; Cirring \& Rowland, 1985; Wetherby \& Prutting, 1984). A capacidade para rejeitar objetos e atividades (protesto) apareceria primeiro seguida pela habilidade em solicitar assistência para a realização de ações (e após, objetos). Por último, surgiria a capacidade para chamar a atenção para o self e para as propriedades dos objetos ou eventos a seu redor.

Durante a fase triádica da comunicação, três categorias de comportamentos foram identificadas (Mundy \& Sigman, 1989): 1) Afiliação, a qual consiste na utilização de comportamentos não-verbais e de uso de objetos para eliciar e manter o foco de atenção no próprio self (ex: 
jogos sociais como esconde-esconde, rolar a bola para o parceiro, etc.); 2) Regulação, a qual consiste de comportamentos de pedido para buscar assistência quanto à aquisição de objetos ou execução de tarefas (ex: acionar um brinquedo); e, 3) Atenção compartilhada, a qual envolve a coordenação da atenção entre "parceiros sociais" com fins de compartilhamento da experiência com objetos/ eventos, a qual será detalhada a seguir.

\section{Atenção Compartilhada}

A habilidade de atenção compartilhada tem sido definida como os comportamentos infantis os quais revestem-se de propósito declarativo, na medida em que envolvem vocalizações, gestos e contato ocular para dividir a experiência em relação às propriedades dos objetos/eventos a seu redor (Mundy \& Sigman, 1989).

Bruner (1978) argumentou que os jogos sociais têm um papel importante no desenvolvimento da habilidade de compartilhar interesses. Ele salientou que o bebê, ao tomar parte de uma mesma atividade repetidamente, passa a entender as demandas e as formas apropriadas de comunicação (culturalmente determinadas), requeridas por uma determinada atividade. $\mathrm{O}$ autor chama a atenção para a natureza ritualista dessas atividades, assim como de outras que fazem parte do cotidiano do bebê (situações de alimentação, higiene, etc.) que, por sua repetição freqüente, facilitariam o desenvolvimento da comunicação intencional.

Tanto as teorias da meta-representação do desenvolvimento social quanto as afetivas (Baron-Cohen \& Bolton, 1993; Hobson, 1993) enfatizam o papel da atenção compartilhada para o desenvolvimento da capacidade simbólica. Durante atividades conjuntas, as crianças começam a notar que outras pessoas têm reações diferentes das dela frente às mesmas situações, o que equivale a dizer que elas descobrem que as pessoas conferem diferentes "significados" aos objetos/eventos que as circundam. Em outras palavras, a criança passa a perceber que ela pode atribuir mais do que uma representação a uma entidade e cada vez mais passa a trocar com o parceiro tais descobertas, utilizando-se de diferentes canais de comunicação. De fato, uma série de estudos investigando o papel da qualidade da atenção compartilhada para o desenvolvimento da linguagem tem apontado para a importância da relação entre esses dois domínios (Akhtar \& Tomasello, 1996; Nelson, 1973; Tomasello \& Farrar, 1986)

Para Butterworth e Jarret (1991) o olhar é uma dimensão especial do comportamento social na medida em que se torna um indicador de interesse e atenção para um observador. A monitorização do olhar refere-se à habilidade da criança em seguir a direção do olhar ou a Psicologia: Reflexão e Crítica, 2002, 15(1), pp. 77-88 tendência em alternar o olhar entre a pessoa e o objeto de interesse como, por exemplo, um brinquedo que precisa ser acionado, mecanicamente. Durante o primeiro ano de vida da criança, a habilidade de atenção compartilhada emerge como resultado da monitorização do olhar entre mãe e bebê. Aos seis meses de idade os bebês são capazes de seguir o olhar da mãe apenas dentro do seu próprio campo visual, porém aos 18 meses, esse "alcance" visual amplia-se.

O emprego de gestos inclui tanto a produção quanto a compreensão de gestos produzidos por outros, durante a ocorrência de atenção compartilhada. Apontar, por exemplo, emerge como uma função de compartilhar a atenção e interesse com o parceiro. Franco e Butterworth (1991, citado em Messer, 1997) elaboraram essa posição através da utilização de uma seqüência de desenvolvimento da função comunicativa do gesto de apontar e a sua progressiva coordenação com a monitorização do olhar. Os autores reportaram que aos 12 meses de vida, as crianças, tipicamente, olham para o parceiro, após apontar. Aos 14 meses, o ato de apontar acompanha o olhar para o parceiro e, aos 16 meses, o olhar precede o gesto, sugerindo progressos na habilidade de compreender a importância de tal gesto ao direcionar o olhar do parceiro para o seu próprio foco de interesse.

Apontar para brinquedos que estão a uma certa distância não é uma atividade comum até o final do primeiro ano de vida. Os dados que confirmam essa posição provêm de vários estudos (Franco \& Butterworth, 1991, citado em Messer, 1997; Messer, 1994; Schaffer, 1984). Um dos estudos investigando a habilidade da criança em seguir o gesto de apontar feito pela mãe, mostrou que enquanto bebês de nove meses tinham condições de seguir apenas informações simples, tais como deslocar o olhar da mão materna para o objeto, os de 14 meses podiam localizar um objeto seguindo movimentos mais complexos dos gestos maternos (Franco \& Butterworth).

Ainda com relação ao gesto de apontar, um dos resultados mais importantes do estudo de Bates e colaboradores (1979) ao investigar a produção de gestos indicativos como apontar, alcançar, mostrar e dar objetos, em um estudo longitudinal, foi o de que o gesto de apontar foi um preditor da capacidade lingüística subseqüente.

Paul e Shiffer (1992), ao estudarem os comportamentos de atenção compartilhada, contemplando mais especificamente a fala, em crianças com desenvolvimento típico, encontraram que a atenção compartilhada consistia em comentários e perguntas para obter informações sobre as propriedades dos objetos ou eventos. Contudo, 
a vasta maioria dos atos comunicativa foi comentários, em contraste com a menor ocorrência de perguntas para obter informação/esclarecimento - um resultado similar ao encontrado por Wetherby e Prutting (1984).

A revisão das teorias e pesquisas apresentadas acima, enfocando principalmente a habilidade de atenção compartilhada, sugere que o desenvolvimento da comunicação e da interação social possui uma natureza organizacional, envolvendo os domínios cognitivos, neurobiológicos e sócio-emocionais. Depreende-se da revisão acima, que um distúrbio, degeneração ou distorção na integração de processos cognitivos, neurobiológicos e sócio-emocionais poderia resultar em patologia, sendo o autismo o exemplo mais intrigante.

\section{Déficits em Atenção Compartilhada e Autismo}

O desenvolvimento de indivíduos com autismo é caracterizado por déficits na comunicação e na interação social. Entretanto, chama-se a atenção para o retrato caricaturado desses indivíduos como sendo "nãocomunicativos e não-interativos". Há evidências substanciais de que crianças com autismo engajam-se e respondem interações sociais (Capps, Sigman \& Mundy, 1994) apresentam comportamentos afiliativos (ex: carinhos), vocalização em direção ao parceiro, participação em brincadeiras e comportamentos indicativos de apego (Capps e cols., 1994; Mundy \& Sigman, 1989). Apesar de se questionar a natureza recíproca desses comportamentos, a sua ocorrência ajuda a refutar a idéia de que uma criança com autismo evita, persistentemente, a interação social, conforme acreditava Richer (1976). Essas evidências apontam para a necessidade de revisão das noções referentes aos indicadores de autismo ainda no primeiro semestre de vida do bebê.

Lord, Storoschuk, Rutter e Pickles (1993) chamaram a atenção para vários fatores que podem afetar a interação social de crianças com autismo, tais como nível global de desenvolvimento e o tipo de contexto no qual a interação ocorre (ex: familiar x não-familiar, estruturado $x$ naturalístico). Tal observação foi confirmada por um outro estudo que buscou investigar, experimentalmente, a influência desses fatores no comportamento sóciocomunicativo de crianças pré-escolares com autismo (Bosa, 1998). A autora demonstrou que a capacidade de atenção compartilhada, apesar de não estar completamente ausente no grupo de crianças com autismo, distinguiu esse grupo dos de controle. A freqüência de $\mathrm{AC}$ foi significativamente mais baixa no grupo com autismo e sua variação dependeu do contexto e do desenvolvimento global da criança. Por exemplo, no contexto em que as mães eram instruídas a, deliberadamente, não interagirem com a criança (porque estavam ocupadas respondendo um questionário), as crianças dos dois grupos de controle (com atraso de desenvolvimento mas sem autismo, e com desenvolvimento típico, respectivamente) intensificaram a busca pela atenção materna, em contraste com as que apresentavam autismo, as quais permaneceram envolvidas em suas próprias atividades.

Lord e colaboradores (1993) salientaram que as diferenças entre grupos de crianças com autismo, quando comparadas a grupos de controle (ex: Síndrome de Down) são particularmente dramáticas quando alguma forma de reciprocidade na interação é levada em conta, explicando-se assim, as diferenças na habilidade de atenção compartilhada. Já na década de 70, Curcio (1978) foi um dos primeiros a documentar o comprometimento na habilidade de atenção compartilhada, em crianças com autismo. Mais tarde, Wetherby e Prutting (1984) comprovaram a ocorrência de déficits nessa área mas chamaram a atenção para o fato de que os comportamentos comunicativos para solicitar assistência estavam intactos. Loveland e Landry (1986) não apenas confirmaram esses resultados mas também demonstraram que tal comprometimento estendia-se à capacidade de seguir a direção do olhar de outras pessoas.

Desde então, os resultados de vários estudos experimentais (Mundy, Sigman \& Kasari, 1994; Mundy, Sigman, Ungerer \& Sherman, 1986; Robertson, Tanguay, L'Ecuyer, Sims \& Waltrip, 1998) têm apontado para essa direção - comprometimento consistente em medidas tanto de produção quanto de compreensão de atos protodeclarativos (atenção compartilhada), em contraste com os protoimperativos (busca de assistência) e outras formas de comportamento social (afiliativos). Mundy e colaboradores (1986), ao investigarem os comportamentos sócio-comunicativos de crianças com autismo, utilizaram uma situação estruturada de interação criançaexperimentador. O grupo de crianças com autismo distinguiu-se dos grupos de controle (deficiência mental e um grupo não-clínico) quanto a capacidade de mostrar/ apontar para objetos e quanto ao olhar de referência (ex: olhar para o parceiro após completar uma tarefa). Além disso, o olhar referencial foi o melhor preditor na discriminação de crianças com e sem autismo. Déficits na capacidade de seguir o olhar do experimentador acompanhado ou não por gestos - também foram reportados.

Um outro estudo, conduzido por Mundy e colaboradores (1994), ao medir o comportamento sóciocomunicativo de crianças com autismo, deficiência mental e desenvolvimento típico, concluiu que o grupo com autismo mostrou comprometimentos numa grande variedade dos 
comportamentos investigados, sendo o mais significativo, o da atenção compartilhada.

Vários estudos buscaram compreender o comprometimento da atenção compartilhada na área do autismo, examinando, por exemplo, formas específicas do gesto de apontar (Goodhart \& Baron-Cohen, 1993) e o papel do olhar nesse processo (Philips, Baron-Cohen $\&$ Rutter, 1992). Goodhart e Baron-Cohen encontraram que o gesto de apontar pode ocorrer em situações nãosociais em oposição ao gesto protodeclarativo, que aparece na atenção compartilhada. Os autores elaboraram a noção acerca do papel do olhar no processo de atenção compartilhada ao sugerirem que a compreensão da direção do olhar funciona como uma importante fonte de informação sobre as intenções e metas do parceiro durante a interação, conforme assinalado anteriormente.

Philips, Baron-Cohen e Rutter (1992) testaram ess noção utilizando-se de uma situação experimental na qua a ação do experimentador era, ou ambígua na sua meta (encorajando e bloqueando simultaneamente a ação da criança em direção a um brinquedo), ou clara (dando um brinquedo para a criança). $\mathrm{Na}$ situação ambígua, as crianças dos grupos de controle (com desenvolvimento típico e com deficiência mental, emparelhados em idade mental) fizeram contato ocular imediato, enquanto as do grupo com autismo, não. Para os autores, o olhar imediato para o adulto teria a função de "busca de informação" sobre o significado da ação ambígua do adulto, o que parecia não ocorrer no grupo com autismo.

A habilidade de atenção compartilhada é tanto um preditor quanto um correlato do desenvolvimento da linguagem em crianças com autismo. Os dados apoiando essa visão são provenientes de um estudo (Mundy, Sigman \& Kasari, 1994) demonstrando que o comportamento de atenção compartilhada foi um preditor mais poderoso do desenvolvimento da linguagem do que o nível da fala ou QI, obtidos no início do estudo.

Retomando-se os estudos apresentados, torna-se evidente, em indivíduos com autismo, a dissociação entre a habilidade de usar os mesmos gestos (apontar, mostrar, etc.) para buscar assistência e para compartilhar a experiência em relação às propriedades dos objetos/eventos circundantes. Tal fenômeno levou os pesquisadores a investigar os mecanismos envolvidos em ambas as atividades, identificando similaridades e diferenças nesses processos. Diante desse panorama, o papel do afeto enquanto um sinalizador de intenções foi ressaltado.

Bruner (1981) reconheceu que as diferenças na atividade não-verbal em situações de busca de assistência ou de compartilhamento de experiências poderiam ser identificadas com base em algum "marcador afetivo". Essa predição foi investigada, experimentalmente, por Mundy, Kasari e Sigman (1994), ao examinarem a relação entre a expressão do afeto e da atenção compartilhada em crianças com desenvolvimento típico. A freqüência e a duração de comportamentos de pedido e de atenção compartilhada foram medidas em crianças de 20 meses de idade. Sinais afetivos faciais (ex: sorriso) foram codificados, independentemente. Os resultados mostraram que a expressão de "afeto positivo" estava mais associada ao comportamento de atenção compartilhada do que ao de pedido. Da mesma forma, Bosa (1998) encontrou que a freqüência de sorrisos, durante uma sessão de interação, não distinguiu crianças com autismo das dos grupos de controle. Isso só ocorreu quando a coocorrência de sorriso com o comportamento de atenção compartilhada foi levada em conta, mesmo controlandose a baixa freqüência deste último comportamento, no grupo com autismo. O déficit de atenção compartilhada encontrado em grupos de crianças com autismo parece envolver, então, distúrbios em processos tanto cognitivos quanto afetivos, sendo que diversos estudos corroboraram essa noção (Dawnson \& Levy, 1989; Snow, Hertzig \& Shapiro, 1987; Trad, Bernstein, Shapiro \& Hertzig, 1993).

Considerando que a habilidade de atenção compartilhada emerge no segundo semestre de vida do bebê e as evidências de que essa capacidade tem distinguido grupos de crianças com autismo daqueles com outros transtornos do desenvolvimento, justifica-se a sua posição como um importante e fidedigno indicador precoce de autismo. Isso não significa que não haja outros indicadores de possíveis comprometimentos, aparentes já nos primeiros meses.

Um estudo utilizando a análise de vídeos caseiros durante o primeiro semestre de vida do bebê, os quais foram, posteriormente, diagnosticados como apresentando autismo, identificaram comprometimentos quanto ao contato ocular, sorriso e balbucio, durante a interação com suas mães (ex: Sparling, 1991). Isso ocorreu mesmo na ausência de quaisquer problemas observáveis quanto ao estilo interativo materno, ao contrário dos achados do estudo de Massie (1978), por exemplo, o qual demonstrou que mães de bebês mais tarde diagnosticados como "autistas" apresentaram menor freqüência de contato ocular e toque físico, comparadas às mães de bebês com desenvolvimento típico. Para Trevarthen, Aitken, Papoudi e Robarts (1996) esses comportamentos podem ser considerados como reativos ao perfil idiossincrático dos seus bebês.

Um dos únicos estudos brasileiros a investigar a interação inicial entre um bebê com suspeita de autismo e sua mãe foi o de Nogueira, Seabra e Seidl de Moura (2000). As autoras compararam as interações de um bebê 
de 1 mês de idade, cujo desenvolvimento, mais tarde, levou à suspeita de autismo, com a de um bebê com desenvolvimento típico. Os achados foram de que o bebê com suspeita de autismo, apresentou menor freqüência de contato visual, comparado ao outro bebê e nenhum episódio de interação com sua mãe, ao contrário da outra díade.

Um aspecto importante que dificulta a generalização dos achados relativos ao primeiro semestre de vida é que um terço das crianças com autismo não apresenta indicadores comportamentais de comprometimentos no desenvolvimento nesse período, seja através de observação de vídeos domésticos ou de entrevistas com os pais (Trevarthen, 1996). Outra questão é a carência de estudos empregando grupos de controle uma vez que problemas de interação face-a-face ocorrem também, por exemplo, em bebês com deficiência sensorial ou mental, filhos de mães com depressão severa ou outra condição psiquiátrica (esquizofrenia ou psicose puerperal) ou em privação social (Rutter \& Lord, 1994; Trevarthen, 2000; Trevarthen e cols., 1996).

Déficits em Atenção Compartilhada e Autismo: Principais Modelos Psicológicos

Os modelos explicativos de Baron-Cohen (1995), Mundy e Sigman (1989) e Hobson (1993) sobre o comprometimento nas áreas afetivas e de atenção compartilhada representam uma grande contribuição ao nosso entendimento acerca dos processos envolvidos na relação entre esses dois domínios do comportamento. A principal diferença entre esses modelos reside na ênfase dada aos sistemas afetivos ou cognitivos, na explicação do comprometimento na habilidade de atenção compartilhada, estabelecendo-se uma espécie de primazia de um sistema sobre outro.

Enquanto o modelo de Baron-Cohen (1995) concentrase nos aspectos cognitivos da atenção compartilhada, tais como atenção, meta e intenção - e a relação desses com o olhar em direção ao parceiro - os outros dois modelos (isto é, o de Mundy e Sigman, e o de Hobson) ressaltam os processos afetivos. Apesar dos dois modelos "afetivos" apresentarem muitos aspectos em comum, diferenças também podem ser identificadas, seja na expressão ou percepção do afeto. Essas questões serão re-examinadas a seguir, iniciando-se pelas idéias de Baron-Cohen.

O modelo desenvolvido por Baron-Cohen (1995) postula que o comprometimento na habilidade de atenção compartilhada parte de um prejuízo no mecanismo denominado SAM (Shared Attention Mechanism), o qual permite que a criança determine (e "cheque") se ela própria e o parceiro estão olhando para o mesmo objeto/evento.
Esse mecanismo, combinado com o de Detector de Intencionalidade (Intentionality Detector - ID) e o de Detector de Direção do Olhar (Eye Direction Detector - EDD) constituem os fundamentos da Teoria da Mente habilidade para atribuir estados mentais ao self e ao outro e de prever o comportamento com base nesses estados (Baron-Cohen \& Bolton, 1993; Baron-Cohen, Leslie \& Frith, 1985). Baron-Cohen (1995) postulou que o SAM pode ser implementado através de diferentes modalidades (visão, tato ou audição), recebendo informações do EDD, ainda que o canal visual seja o mais fácil de ser utilizado para essa tarefa. Isso explicaria o motivo pelo qual crianças com deficiência visual compensariam dificuldades nessa área, utilizando-se de outros canais sensoriais na atividade de atenção compartilhada (por exemplo, "apalpando" o objeto a ser compartilhado). Entretanto, crianças com autismo aparentemente demonstram dificuldades no uso de qualquer uma dessas modalidades sensoriais. Baron-Cohen (1995) ilustra bem essa noção ao descrever o caso de uma criança com deficiência visual severa que ao ser solicitada por sua mãe a "deixá-la ver" o carrinho com o qual brincava, acenou com o mesmo na mão, assim como empregou palavras como "veja" ou "olhe" ao chamar a atenção de sua mãe para os brinquedos. Isso sugere que essas crianças parecem compreender que "ver" significa explorar um objeto, perceptualmente.

Em relação às habilidades protoimperativas - as quais tendem a não se apresentar como problemáticas em se tratando de autismo - Baron-Cohen (1995) esclarece que tais comportamentos não envolvem atenção compartilhada por serem primordialmente "instrumentais" e, aparentemente, não indicarem um desejo de compartilhar interesse com o parceiro pelo simples prazer do compartilhamento.

Quanto às teorias afetivas, Hobson (1993) atribui o comprometimento na habilidade de atenção compartilhada e na expressão do afeto em crianças com autismo, a dificuldades quanto ao conceito a respeito da mente de outras pessoas e consciência do próprio self, o que por sua vez, decorre da inabilidade de se relacionar com outras pessoas. Para o autor, mecanismos inatos operam no sentido de permitir atitudes interpessoais coordenadas entre o bebê e os outros de tal modo que o símbolo (linguagem verbal e não-verbal) envolvido no processo de compartilhamento, torna-se possível.

O amálgama da teoria afetiva de Hobson (1993) é a capacidade do bebê em perceber e reagir às atitudes expressas pelos outros, através do corpo. Tal processo permite a emergência da capacidade de compreender "pessoas com mentes" através do que ele chama de 
"coordenação afetiva" - uma habilidade que é essencial para o engajamento interpessoal. Essa experiência permite ao bebê compreender de que forma as pessoas diferem de "coisas". Ao fazer isso, o bebê desenvolve uma consciência de que as pessoas têm atitudes em relação ao ambiente semelhantes às dele, ao mesmo tempo em que percebe que as pessoas conferem significados diferentes para as mesmas situações - noção similar a proposta por Bruner (1981) ao descrever a importância dos jogos sociais, durante a interação mãe-bebê. Contudo, para Hobson, a ênfase é na natureza afetiva dessas atitudes - a qual toma a forma de expressões facial, vocal e gestual - e na capacidade inata do bebê para perceber "significado" emocional nessas expressões, tal qual sugerido por Kanner (1943).

Buscando uma alternativa integrativa, Mundy e Sigman (1989) propuseram um modelo que considera a habilidade de atenção compartilhada como um reflexo de processos tanto afetivos quanto cognitivos. Déficits na área de atenção compartilhada derivariam de dificuldades na capacidade para dividir e comparar as experiências afetivas com outras pessoas em relação a um terceiro referente (objeto/evento ou outra pessoa). Tal habilidade permite à criança desenvolver o que os autores denominam de "esquemas de ação social" a partir da interação face-a-face. Esse esquema baseia-se na representação do afeto (do self e dos outros) que se daria através da comparação das experiências internas dos outros com as expressões afetivas que as acompanham. Tais experiências são então contrastadas com as da própria criança, no mesmo tipo de situação. Ou seja, a informação proprioceptiva (ex: movimentos dos músculos faciais), eliciada por um referente externo (ex: jogos sociais), é comparada com a informação afetiva percebida nos outros em relação ao mesmo referente. A troca de sorrisos durante os chamados jogos sociais ilustra essa noção. Nesse sentido, o processo de comparação das experiências afetivas do próprio self com o do outro é o ponto central da abordagem proposta por esses autores e não a percepção do afeto per se, enfatizada na teoria afetiva de Hobson (1993).

Mundy e Sigman (1989) especularam que esse processo é rudimentar nos seis primeiros meses de vida do bebê. As trocas afetivas em relação a objetos/eventos constituem os alicerces sobre os quais se desenvolverá a comunicação não-verbal triádica - habilidade que emerge no período seguinte do desenvolvimento do bebê, expandindo a sua capacidade sócio-cognitiva. Esses autores explicam a transição desse processo rudimentar para as habilidades de representação mais complexas por uma referência à crescente habilidade do bebê em integrar representações do seu próprio afeto com as dos outros - um processo simbólico por si só, segundo esses autores.
Investigações experimentais a respeito do desenvolvimento da atenção compartilhada e do afeto em crianças com autismo (Dawson \& Lewy, 1989; Mundy e cols., 1986) têm identificado respostas afetivas atípicas diante de estimulação, incluindo a social - mais especificamente, distúrbios na auto-regulação da reação emocional (arousa), assim como, um comprometimento no desenvolvimento da capacidade simbólica. Essa noção já havia sido discutida por Hutt e Hutt (1968) e mais tarde expandida por Ornitz e Ritvo (1976). A característica marcante dessas teorias é a atribuição dos déficits sociais a dificuldades em modular experiências sensoriais e perceptivas. Em outras palavras, postula-se que a criança com autismo experienciaria um estado crônico de superexcitação (overarousal) (Hutt \& Hutt) ou uma flutuação entre estados de hipo e hiperexcitação (Ornitz \& Ritvo) que a levaria a apresentar reações emocionais intensas, aversão à fixação do olhar e retraimento social, enquanto mecanismos de redução dos altos níveis de excitação. A conseqüência seria o bloqueio ao desenvolvimento das relações sociais, mais especificamente, da habilidade de atenção compartilhada.

Concluindo, os modelos apresentados acima, ressaltam a importância de ambos os sistemas (afetivos e cognitivos) envolvidos na atenção compartilhada, numa tentativa de compreender os mecanismos implicados no desenvolvimento dessa capacidade ou, ao contrário, na limitação desse processo. Apesar de ocorrerem divergências quanto à ênfase na primazia de um sistema sobre o outro (afetivo ou cognitivo), a noção de que ambos os sistemas são elementos importantes do desenvolvimento social não tem sido desafiada.

Ressalta-se que a discussão acima centrou-se apenas nos modelos apresentados por serem as abordagens psicológicas mais amplamente debatidas na literatura pertinente. Entretanto, chama-se a atenção para a existência de outros modelos como o neuropsicológico e do processamento da informação os quais focalizam a relação entre cérebro e comportamento social, como por exemplo, função executiva e atenção compartilhada (Bosa, 2001).

Uma crítica aos modelos neuropsicológicos diz respeito à ênfase na habilidade de atenção compartilhada como um processo dependente apenas de competências internas da criança. Postula-se que, particularmente importante, é a compreensão do desenvolvimento da comunicação intencional inserido num contexto de interação social. Num trabalho anterior já se chamou a atenção para o fato de que ambos os elementos de uma díade contribuem para a qualidade da interação (Bosa \& Piccinini, 1994). Um aspecto a ser ressaltado, é a importância de focalizar-se não somente as competências sociais do 
bebê, mas também os fatores maternos que facilitam ou, ao contrário, inibem o desenvolvimento da linguagem. Por exemplo, diferentes estudos têm investigado a relação entre o estilo de interação materna e as competência lingüísticas do bebê (Akhtar, Dunham \& Dunham, 1991; Nelson, 1973), demonstrando que estratégias maternas que visam o engajamento da criança em atividades e que partem do interesse do próprio bebê (em oposição a um estilo mais diretivo, focalizado no interesse da própria mãe) têm associação com o desenvolvimento do vocabulário. Chama-se a atenção para a necessidade de levarse em conta aspectos do cuidador, como por exemplo, estratégias de interação e sensibilidade aos sinais infantis. Dessa forma, sugere-se, por exemplo, a investigação da relação entre apego cuidador-criança e comunicação intencional em crianças com autismo, a exemplo do que Bates e colaboradores (1979) fizeram em crianças com desenvolvimento típico. No caso de familiares de indivíduos com autismo, a literatura é repleta de evidências demonstrando o estresse familiar (em especial depressão materna) e a falta de uma rede de apoio social a essas famílias, o que poderia contribuir para dificuldades quanto à sensibilidade em perceber os sinais infantis, durante a interação. Por exemplo, Bosa (1998) investigou a relação entre atenção compartilhada e estresse materno, encontrando que apesar de mães de crianças com autismo apresentarem indicadores de estresse mais altos que as mães dos grupos de controle (em especial distúrbios psicossomáticos), não encontrou associação positiva entre esses dois domínios. Ou seja, filhos de mães com níveis mais altos de estresse mostraram habilidades de atenção compartilhada tanto quanto filhos de mães com escores mais baixos em medidas de estresse materno, mesmo quando o tipo de patologia da criança foi controlado. Entretanto, artefatos metodológicos podem ter impedido a identificação dessa relação, como por exemplo, a natureza estruturada das observações das interações. Especula-se ainda, se o desconhecimento das famílias acerca do desenvolvimento infantil, independente da condição clínica da criança, seria um fator que contribuiria para as dificuldades de interação de crianças com transtornos do desenvolvimento e seus cuidadores.

O reconhecimento dos comprometimentos na comunicação não-verbal, seja qual for o modelo teórico adotado na sua compreensão, abre espaço para identificação precoce de crianças que estão em risco quanto ao desenvolvimento psicolinguístico e da interação social, incluindo o espectro autista. Em outros países, as evidências acumuladas nessa área têm servido de suporte para programas de rastreamento dos transtornos invasivo do desenvolvimento em torno dos 18 meses de vida do bebê (Baron-Cohen, Allen \& Gilbberg 1992). Considerando-se que o melhor preditor do desenvolvimento social subseqüente, em crianças com autismo, é o nível de linguagem funcional desenvolvido até os cinco anos de idade (Rutter \& Lord, 1994), as implicações dessa tarefa para intervenções, ainda no período pré-escolar, são óbvias.

\section{Conclusão}

A proposta desse trabalho foi a de apresentar evidências sobre o potencial preditivo do comportamento de atenção compartilhada como indicador precoce do autismo. Argumentou-se que as discussões sobre atenção compartilhada, apesar de extensas, carecem de bases epistemológicas. $\mathrm{Na}$ tentativa de preencher essa lacuna, partiu-se da compreensão do desenvolvimento da habilidade de atenção compartilhada, com base nas suas relações com os conceitos de intencionalidade e comunicação. Buscou-se ainda a articulação desses conceitos com estudos longitudinais, principalmente da área sóciocognitiva. Cabe lembrar que o termo "cognitivo" presta-se a inúmeras confusões, conforme apontado por Bruner (1990/1997). Portanto, é necessário esclarecer que a área sócio-cognitiva, de acordo com Carpenter e colaboradores (1998), trata, fundamentalmente, do processo de compreensão dos outros como agentes psicológicos, enquanto integração de processos afetivos e cognitivos.

Em seguida, abordou-se as evidências e inconsistências dos achados sobre os indicadores precoces de autismo. $\mathrm{O}$ que de fato concebe-se como "precoce"? O quanto se deve "retroceder" na linha do tempo para que um dado comportamento seja um indicador confiável dos futuros comprometimentos, característicos do espectro autista?

Apontou-se que as informações sobre o desenvolvimento inicial de bebês, mais tarde diagnosticados como "autistas", têm sido controversas. Alguns estudos demonstraram que esses bebês tenderam a apresentar menor freqüência de contato olho-a-ollho, sorriso e orientação para a face, durante interações iniciais com suas mães. Há também evidências de menor freqüência do balbucio ou de resposta ao ser chamado pelo nome, em comparação aos bebês de grupos de controle, observados no final do primeiro semestre. Entretanto, outras pesquisas falharam em produzir qualquer evidência de comprometimento nos primeiros meses, seja utilizando a observação de vídeos domésticos ou informações dadas pelos pais. Os resultados de estudos que utilizaram informações retrospectivas levantam a seguinte questão: ou os comprometimentos "sociais" podem, de fato, não estar presentes desde o primeiro semestre de vida do 
bebê ou, ao contrário, estão, mas não são notados pelos pais. As razões podem variar desde sutilezas na expressão das dificuldades até a "negação" das mesmas, pelos pais, passando por inexperiência no convívio com bebês. Nesse caso, os pais não conceberiam os comprometimentos como tais, em função do desconhecimento dos parâmetros de desenvolvimento de um bebê. Já os estudos longitudinais, com base na observação sistemática, sofrem menos interferência de "variáveis intervenientes", porém são extremamente raros. Isso porque a chance de se observa um bebê, em projetos longitudinais, que mais tarde será diagnosticado como "autista", é baixa. Conforme BaronCohen e colaboradores (1992) é como "achar agulha em palheiro". Soma-se a isso as evidências de que a baixa freqüência do contato ocular, do sorriso ou balbucio também pode estar associada a outros quadros, tais como, privação social severa (abandono) e transtornos do apego, atrasos de linguagem e deficiências sensoriais.

Em contrapartida, os comprometimentos observados no final do primeiro ano de vida, em especial na área de atenção compartilhada, têm discriminado crianças com e sem autismo. Defendeu-se a necessidade de integração de modelos afetivos e cognitivos para a compreensão dessa habilidade e de inserir-se o entendimento das competências comunicativas infantis num contexto mais amplo de apego cuidador-bebê. Sugeriu-se, ainda, a possibilidade de se explorar, empiricamente, possíveis relações entre apego e atenção compartilhada, na área da psicopatologia do desenvolvimento, chamando a atenção para aspectos do ambiente tais como qualidade do cuidado, stress familiar e rede de apoio disponível.

Embora a proposta de integração de modelos afetivos e cognitivos possa parecer um tanto "híbrida" ou excessivamente eclética para os que defendem a adoção de um modelo "puro" de desenvolvimento, desafia-se a noção de que a compreensão de determinadas patologias, como o autismo, possa ser compreendida de uma forma singular, calcada num único modelo explicativo. Se levarmos em conta que uma das características mais marcantes do autismo é a dificuldade em colocar-se no ponto de vista do outro (ou seja, transitar nos domínios afetivos e cognitivos alheios), ao abandonarmos esse modelo dito híbrido fica no ar a questão: quem seria o autista afinal de contas?

\section{Referências}

Ainsworth, M. D. S., Blehar, M. C., Waters, E. \& Wall, S. (1978). Patterns of attacbment. Hillsdale, NJ: Lawrence Erlbaum.

Akhtar, N. \& Tomasello, M. (1996). Twenty-four month old children learn words for absent objects and actions. British Journal of Developmental Psychology, 14, 79-93.
Akhtar, N., Dunham, F. \& Dunham, P. J. (1991). Directive interactions and early vocabulary development: The role of joint attentional focus. Journal of Child Language, 18, 41-49.

Austin, J. (1962). How to do things with words. Oxford: Oxford University Press.

Baron-Cohen, S. (1988). Social and pragmatic deficits in autism: Cognitive or affective? Journal of Autism and Developmental Disorders, 18, 379-402. Baron-Cohen, S. (1995). Mindblindness. Cambridge, MA: MIT.

Baron-Cohen, S., Leslie, A. M. \& Frith, U. (1985). Does the autistic child have a 'theory of mind'? Cognition, 21, 37-46.

Baron-Cohen, S., Allen, J. \& Gilbberg, C. (1992). Can autism be detected at 18 months? The needle, the haystack, and the CHAT. British Journal of Psychiatry, 161, 839-843.

Baron-Cohen, S. \& Bolton, P. (1993). Autism: The facts. Oxford University. Baron-Cohen, S. \& Bolton, P. (1993). Autism: The facts. Oxford Unive
Bates, E. (1976). Language and context. New York: Academic Press.

Bates, E., Benigni, L., Bretherton, I., Camaioni, L. \& Volterra, V. (1979). The emergence of symbols: Cognition and communication in infancy. New York: Academic Press.

Bates, E., Camaioni, L. \& Volterra, V. (1979). The acquisition of performatives prior to speech. Em E. Ochs \& B. Schieffeling (Orgs.), Developmental pragmatics (pp. 111-128). London: Academic Press.

Bosa, C. (1998). Affect, social comunication and self-stimulation in cbildren with and witbout autism: A systematic observation study of requesting behaviours and joint attention. Dissertação de Doutorado não-publicada. Institute of Psychiatry, Universidade de Londres, Inglaterra.

Bosa, C. (2001). As relações entre autismo, comportamento social e fun-

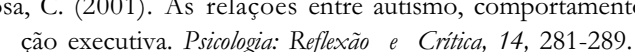

Bosa, C. \& Piccinini, C. (1994). Temperamento infantil e apego mãecriança: Considerações teóricas. Psicologia: Teoria e Pesquisa, 10(2), 193-
cha 212.

Bruner, J. (1978). Acquiring the uses of language. Canadian Journal of Psychology, 32, 204-218

Bruner, J. (1981). The social context of language as acquisition. Language and Communication, 1(2-3), 155-178.

Bruner, J. (1997). Atos de significacãa (S. Costa, Trad. ). Porto Alegre: Artes Médicas. (Original publicado em 1990)

Bushnell, I. W., Sai, F. \& Mullin, J. T. (1989). Neonatal recognition of the mother's face. British Journal of Developmental Psychology, 7, 3-15.

Butterworth, G. \& Jarrett, N. (1991). What minds have in common is space: Spatial mechanisms serving joint visual attention in infancy. British Journal of Developmental Psychology: Special Issue, 9, 55-72.

Carvalho, A. M. A. (1998). Etologia e comportamento social. Em L. de Souza, M. M. P. Rodrigues \& M. F. Q. Freitas (Orgs.), Psicologia: Reflexóes (im)pertinentes (pp. 195-224). São Paulo: Casa do Psicólogo.

Capps, L., Sigman, M. \& Mundy, P. (1994). Attachment security in children with autism. Development and Psychopathology, 6, 249-261.

Carpenter, R. L., Mastergeorge, A. M. \& Coggins, T. E. (1983). The acquisition of communicative intentions in infants 8-15 months of age. Language and Speech, 26, 101-116.

Carpenter, M., Nagell, K. \& Tomasello, M. (1998). Social cognition, joint attention and communicative competence from 9 to 15 months of age. Monographs of the Society for Research in Child Development, 63 (4, Serial No 255).

Cirring, F. M. \& Rowland, C. M. (1985). Communicative assessment of nonverbal youths with severe/profound mental retardation. Mental Retardation, 23, 52-62.

Curcio, F. (1978). Sensorimotor functioning and communication in mute autistic children. Journal of Autism and Developmental Disorders, 8, 281 292.

Dawson, G. \& Lewy, A. (1989). Arousal, attention, and socioemotional impairments of individuals with autism. Em G. Dawson (Org.), Autism: New perspectives on nature, diagnosis, and treatment (pp. 3-21). New York: Guilford Press.

Fogel, A. (1993). Developing through relationships. Chicago: University of Chicago Press. 
Goodhart, F. \& Baron-Cohen, S. (1993). How many ways can the point be made? Evidence from children with and without autism. First Language made? Evidence $225-233$.

Hargie, O., Saunders, C. \& Dickson, D. (1987). Social skills in interpersonal communication. London: Brookline Books.

Hobson, P. (1993). Understanding persons: The role of affect. Em S. Baron-Cohen, H. Tager-Flusberg \& D. J. Cohen (Orgs.), Understanding other minds: Perspectives from autism (pp. 205-227). Oxford: Oxford Medical Publications.

Hutt, C. \& Hutt, S. J. (1968). Stereotypy, arousal and autism. Human Development, 11, 277-286.

Kanner, L. (1943). Affective disturbances of affective contact. Nervous Child, 2, 217-250.

Kaye, K. (1982). The mental and social life of babies. Chicago: University of Chicago.

Lyra, M. C. D. P. \& Seidl de Moura, M. L. (2000). Desenvolvimento na interasaão social e no contexto bistórico-cultural: Adequasáa entre perspectiva teórica social e no contexto histórico-cultural: Adequacáa entre per.
metodologia. Psicologia: Reflexão e Crítica, 13, 217-222.

Lord, C. \& Magill, J. (1989). Methodological and theoretical issues in studying peer-directed behavior and autism. Em G. Dawson (Org.), dying peer-directed behavior and autism. Em G. Dawson (Org.),
Autism: Nature, diagnosis and treatment (pp. 327-345). New York: Guilford. Autism: Nature, diagnosis and treatment (pp. 327-345). New York: Guilford.
Lord, C., Storoschuk, S., Rutter, M. \& Pickles, A. (1993). Using the ADI-R Lord, C., Storoschuk, S., Rutter, M. \& Pickles, A. (1993). Using the ADI-R
to diagnose autism in preschool children. Journal of Infant Mental Health, 14, 234-252

Loveland, K. A. \& Landry, S. H. (1986). Joint attention and language in autism and developmental language delay. Journal of Autism and Developmental Disorders, 16, 335-349.

Lyra, M. C. D. P. (2000). Desenvolvimento de um sistema de relações historicamente construído: Contribuições da comunicação no início da vida. Psicologia: Reflexão e Crítica, 13, 257-268.

Lyra, M. C. D. P. \& Moura, M. C. S. (2000). Desenvolvimento na interação social e no contexto sócio-cultural: Adequação entre perspectiva teórica e metodológica. Psicologia: Reflexão e Crítica, 13, 217-222.

Massie, H. N. (1978). The early natural history of childhood pychosis. Journal of the American Academy of Child Psychiatry, 18, 583-591.

Messer, D. (1994). The development of communication: From social interaction to language. Chichester, UK: John Wiley \& Sons.

Messer, D. (1997). Referential communication: Making sense of the social and physical worlds. Em G. Bremmer, A. Slater \& G. Butterworth (Orgs.), Infant development: Recent advances (291-306). East Sussex, UK Psychology Press.

Mundy, P., Sigman, M., Ungerer, J. A. \& Sherman, T. (1986). Defining the social deficits of autism: The contribution of nonverbal communication measures. Journal of Child Psychology and Psycbiatry, 27, 657-669.

Mundy, P. \& Sigman, M. (1989). Specifying the nature of the social impairment in autism. Em G. Dawson (Org.), Autism: New perspectives on nature, diagnosis, and treatment (pp. 3-21). New York: Guilford.

Mundy, P., Sigman, M. \& Kasari, C. (1994). Joint attention, developmental level and symptom presentation in autism. Development and Psychopathology, 6, 389-401.

Nelson, K. (1973). Structure and strategy in learning to talk. Monographs of the Society for Research in Child Development, 38, (1-2, Serial No. 149).

Nogueira, S. E., Seabra, K . \& Seidl de Moura, M. L. (2000) Diagnóstico precoce de autismo e desenvolvimento infantil inicial: Um estudo
prestali precoce de autismo e desenvolvimento infantil inicial: Um estudo
comparativo de dois bebês com um mês de vida. [Resumos]. Em Sociedade Brasileira de Psicologia (Org), Anais, XXX Reunião Anual de Psicologia (p. 138), Brasília, DF : SBP
Ornitz, E. M., \& Ritvo, E. R. (1976). The syndrome of autism: A critical review. The American Journal of Psychiatry, 133, 609-621.

Pantoja, A. P. F. \& Nelson-Goens, G. C (2000). Desenvolvimento da vida emocional durante o segundo ano de vida: Narrativas e sistemas dinâmicos. Psicologia: Reflexão e Crítica, 13, 269-280.

Paul, R., \& Shiffer, M. (1992). Communicative initiations in normal and late-talking toddlers. Applied Psycholinguistics, 12, 420-431.

Philips, W., Baron-Cohen, S. \& Rutter, M. (1992). Development and Psychopatbology, 4, 375-383.

Richer, J. (1976). Social avoidance behaviour of autistic children. Animal Behavior, 24, 898-906.

Robertson, J. M., Tanguay, P., L’Ecuyer, S., Sims, A. \& Waltrip, C. (1998). Domains of social communication handicap in autism spectrum disorder. Journal of American Academy of Child and Adolescence Psycbiatry, 38, 738-745.

Rutter, M. \& Lord, C. (1994). Autism and pervasive developmental disorders. Em M. Rutter, E. Taylor \& L. Hersov (Orgs.), Child and adolescent psycbiatry: Modern approaches (pp. 569-615). Oxford: Blackwell Science. Scaife, M. \& Bruner, J. (1975). The capacity for joint attention in the infant Nature, 253, 265-266.

Searle, J. (1965). Speech acts. Cambridge: Cambridge University of Press. Seidl de Moura, M. L. \& Ribas, A . F. P. (2000). Desenvolvimento e contexto sociocultural: A gênese da atividade mediada nas interações iniciais mãe-bebê. Psicologia: Reflexão e Crítica, 13, 245-256.

Snow, M. E., Hertzig, M. E. \& Shapiro, T. (1987). Expression of emotion in young autistic children. Journal of the American Academy of Child and Adolescent Psychiatry, 26, 836-838.

Sparling, J. W. (1991) Brief report: A prospective case report of infantile autism pregnancy to four years. Journal of Autism and Developmental Disorders, 21, 229-236.

Tomasello, M. \& Farrar, M. J. (1986). Joint attention and early language. Child Development, 57, 1454-1463.

Trad, P. V., Bernstein, D., Shapiro, T. \& Hertzig, M. (1993). Assessing the relationship between affective responsivity and social interaction in relationship between affective responsivity and social interaction in
children with pervasive developmental disorder. Journal of Autism children with pervasive developmen
and Developmental Disorders, 23, 361-377.

Trevarthen, C. (1979). Communication and cooperation in early infancy: A description of primary intersubjectivity. Em M. Bulova (Org.), Before speecb: The beginnings of buman communication (pp. 321-347). London: Cambridge University.

Trevarthen, C., Aitken, K., Papoudi, D. \& Robarts, J. (1996). Children with autism: Diagnosis and interventions to meet their needs. London: Jessica Kingsley. Trevarthen, C. (2000). Intrinsic motives for companioship in understanding: their origin, development, and significance for infant mental health. Infant Mental Health Journal, 22, 95-131.

Vygotsky, L. S. (1978). Internalization of higher psychological functions. Em M. Cole, V. John-Steiner, S. Scribner \& E. Souberman (Orgs.), Mind and society: The development of bigher psychological processes (pp. 52-67). Cambridge, MA: Harvard University.

Walton, G. E., Bower, N. J. A. \& Bower, T. G. R. (1992). Recognition of familiar faces by newborns. Infant Behaviour and Development, 15, 265-269. by cognitive-social abilities in autistic children. Journal of Speech and Hearing
Research, 27, 364-377.

Recebido: 26/12/2000 Revisado: 16/06/2001 Aceito: 19/11/2001

Sobre a autora

Cleonice Bosa é Psicóloga, Especialista em Psicopedagogia Terapêutica, Mestre em Psicologia do

Desenvolvimento pela Universidade Federal do Rio Grande do Sul e PhD em Psicologia pelo Instituto de Psiquiatria, Universidade de Londres, Professora do PPG em Psicologia do Desenvolvimento da Universidade Federal do Rio Grande do Sul e Coordenadora do Núcleo Integrado de Estudos e Pesquisa em Transtornos do Desenvolvimento - Nieped, UFRGS. 